Fecha de recepción: marzo 2020 Fecha de aceptación: abril 2020 Versión final: mayo 2020

\section{Interdisciplinariedad entre diseño e ingeniería: Nuevas competencias en la docencia de proyectos para la innovación circular}

\author{
Jorge Lino Alves ${ }^{(1)}$, Claudia Alquezar Facca ${ }^{(2)}$, Adriana \\ Patrícia Fernandes ${ }^{(3)}$, Bárbara Rangel ${ }^{(4)}$, Ana Mae Barbosa ${ }^{(5)}$
}

\begin{abstract}
Resumen: Este artículo analiza la relación entre diseño e ingeniería a través de experiencias de enseñanza interdisciplinarias para crear conciencia sobre la economía circular. La educación es esencial para permitir este proceso de manera sistémica para futuros profesionales en ambas áreas, introduciendo metodologías integradas de proyectos en el diseño de productos y sus medios de producción. El objetivo es que, además de las áreas de especialización (arquitectura, diseño, gestión e ingeniería), se establezcan perspectivas futuras para repensar el camino actual del desarrollo económico. Esto creará una base de habilidades para promover la innovación circular, alineada con la necesidad de que las sociedades modernas avancen hacia un paradigma más sostenible.
\end{abstract}

Palabras clave: Innovación circular - educación - proyecto - diseño - ingeniería - sostenibilidad

[Resúmenes en inglés y portugués en las páginas 202-203]

(1) Nació el 10 de octubre de 1961 en Oporto, Portugal. Licenciado, Faculdade de Engenharia, Master, Faculdade de Engenharia, Oporto, Doctor en Filosofía, Universidad de Lehigh (USA). Investigador y profesor en la Universidad Porto Facultad Ingeniería. Vicepresidente INEGI, Porto. Miembro de la comisión pedagógica FEUP / DEMEGI, Porto

(2) Diseñadora, educadora e investigadora en Diseño, Doctoranda en Diseño (Universidade Anhembi Morumbi), Doutorado Sanduíche (Faculdade de Engenharia da Universidade do Porto), Master en Diseño (Universidade Anhembi Morumbi), Especialista en Comunicación y Artes (Universidade Presbiteriana Mackenzie), graduada en Diseño Industrial con mención en Proyecto de Producto (Universidade Presbiteriana Mackenzie).

(3) Doctoranda en la Universidad de Oporto - FBAUP (Facultad de Bellas Artes) y en la Universidad de Aveiro. Investigador del Design Studio FEUP, Facultad de Ingeniería de la Universidad de Oporto. Profesional de diseño independiente, trabaja en proyectos relacionados con diseño estratégico, economía creativa y diseño para la innovación social. 
(4) Arquitecta, Doctoranda en ingeniería Civil (Universidade do Porto). Colaboró con Rafael Moneo, trabajó con Álvaro Siza. Es editora de la revista Cadernos d'Obra desde 2009, profesora e investigadora en ingeniería civil y diseño industrial (FEUP).

(5) Educadora e investigadora de, Doctora y Master en Educación Artística por la Universidad de Connecticut y la Universidad de Boston (Estados Unidos), Profesora Titular retirada (USP-Universidad de São Paulo), actúa en el Master y Doctorado en Diseño (Universidad Anhembi Morumbi-Brasil). Orden Nacional del Mérito Científico y Orden del Mérito Cultural (2016)

\section{Introdução}

Desde a Revolução Industrial, o modelo económico mundial dominante tem-se baseado no fluxo linear 'tirar-fazer-usar-dispor' de extração de recursos, processamento e transformação de matéria-prima em bens, incluindo seu consumo e descarte, seja como uma refeição, um livro, uma máquina de lavar, um carro ou um edifício (ELLEN MACARTHUR FOUNDATION, 2015; ANDREWS, 2015; BERARDI e DIAS, 2018). Ao mesmo tempo que este modelo foi central para o desenvolvimento industrial e gerou um nível de crescimento sem precedentes, contribuindo para crescimento global, produzindo riqueza, reduzindo o número de pessoas em extrema pobreza, melhorando as condições de vida de maneira geral e impulsionando o grande aumento populacional, acabou por gerar mais consumo e mais emissões de gases poluentes para o ar e resíduos ao longo de toda a cadeia de produção. Metade das emissões de gases com efeito estufa (GEE) a nível mundial deve-se à produção de materiais básicos e 70\% dos resíduos associados a um produto são gerados antes mesmo dele ser utilizado. A economia global funciona à razão de 65 mil milhões de toneladas de materiais extraídos ao ano. Neste ritmo, em 2050 seriam precisos recursos equivalentes a 3 planetas para sustentar o nosso modo de vida (COSTA et al., 2018) (Figura 1). 
2020 | 7,8 mil milhões

2030 | 8,5 mil milhões

2050 | 9,7 mil milhões
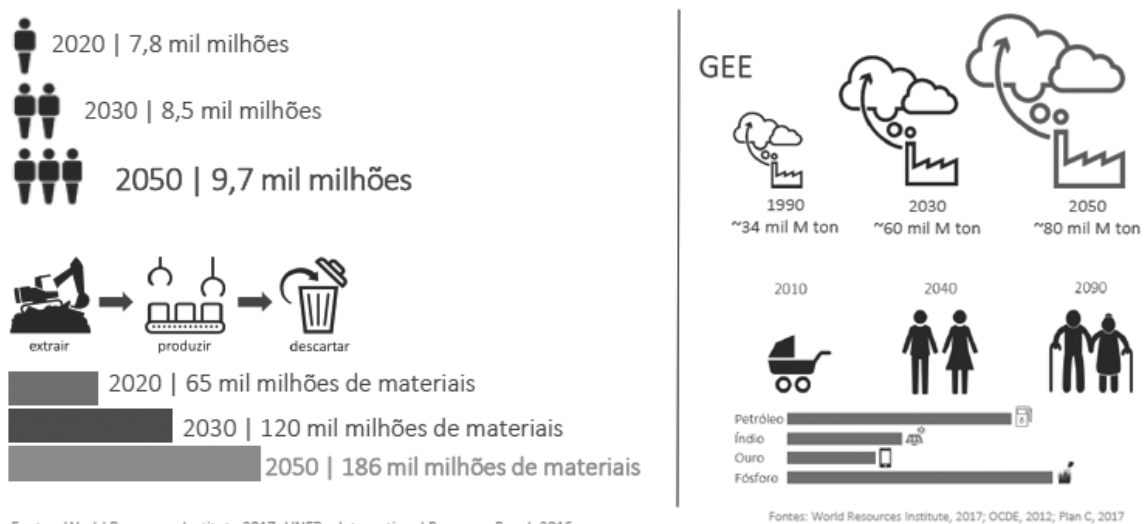

Fontes: World Resources Institute 2017; UNEP - International Resource Panel, 2016

Figura 1. Economia linear = risco e escassez (COSTA et al., 2018).

A economia é uma das principais fontes de problemas ambientais, estando cada vez mais a gerar perdas económicas. Estima-se que a poluição, por exemplo, causa um prejuízo de cerca de US\$ 4,6 trilhões/ano, o que representa cerca de $6 \%$ da produção económica mundial. O mote "crescer agora, limpar depois", cultivado por muitos países durante anos de desenvolvimento económico, não é mais sustentável num mundo cujas fronteiras são ultrapassadas em diversas dimensões e onde é mais dispendioso "limpar mais tarde" do que evitar danos num primeiro momento, gerando impactos negativos muitas vezes irreversíveis à saúde humana (UN ENVIRONMENT, 2019). A obsolescência programada (PACKARD, 1965) aumentou os lucros das empresas, mas, há mais de 50 anos que foi reconhecida como "a tentativa sistemática de fazer com que fossemos indivíduos perdulários, endividados e permanentemente descontentes" (ANDREWS, 2015).

Oferecer uma vida digna e bem-estar para mais de 10 bilhões de pessoas em 2050, sem comprometer os limites ecológicos do nosso planeta, é um dos maiores desafios e responsabilidades da humanidade (UN ENVIRONMENT, 2019).As pressões crescentes sobre o ambiente, exercidas pelo crescimento económico e pelaprocura das populações, ultrapassaram os benefícios que se poderiam retirar desses ganhos de eficiência. O ambiente está intimamente relacionado, de forma positiva e negativa, às questões económicas fundamentais, como a pobreza, a prosperidade, os empregos, os padrões de produção, a inovação e a disponibilidade/escassez de recursos (OECD, 2008).Ações como o Acordo de Paris e os Objetivos de Desenvolvimento Sustentável estabelecidos pela Assembleia Geral das Nações Unidas, ambos assinados em 2015, também passaram a fazer parte formalmente de uma nova agenda de desenvolvimento sustentável, onde países de todo o mundo se comprometeram a minimizar as consequências do aquecimento global. 
A Fundação Ellen MacArthur, instituição inglesa pioneira no que se refere a inspirar a próxima geração para repensar e reconstruir um futuro positivo, apresenta vários fatores que indicam que o modelo linear está a enfrentar um desafio cada vez maior do próprio contexto no qual opera e que é necessária uma mudança mais profunda do modelo operacional da economia atual. São eles: perdas económicas e desperdício estrutural, riscos de preços dos recursos e escassez da oferta, crescente urbanização, degradação dos sistemas naturais, tendências regulatórias para reduzir e avaliar externalidades negativas, avanços tecnológicos para criar novas oportunidades, aceitação de modelos de negócio alternativos, etc. (ELLEN MACARTHUR FOUNDATION, 2015).

Estamos acostumados a pensar na indústria e no meio-ambiente como sendo contrários um ao outro, devido aos métodos convencionais de extração, manufatura e descarte serem nocivos ao mundo natural. Os ambientalistas frequentemente caracterizam os negócios e a própria indústria como maus e inevitavelmente destrutivos. Por outro lado, os industriais veem os ambientalistas como um obstáculo para a produção e o crescimento. Para o meio-ambiente ser saudável, as ações das indústrias deveriam ser reguladas e restritas. Para as indústrias crescerem, a natureza não pode ter precedência. Parece que estes dois sistemas não conseguem prosperar no mesmo mundo (MCDONOUGH e BRAUNGART, 2002).

O design tem neste paradigma um papel determinante. Em todo o processo de produção de um produto, seja ele um objeto ou um edifício, é o designer que sugere e define desde os processos de produção até aos materiais utilizados. Só na última década é que o ciclo de vida do produto começou a fazer parte das preocupações e dos requisitos do projeto. $\mathrm{O}$ tema da sustentabilidade já está presente no currículo de grande parte dos cursos da área do design e de arquitetura bem como de engenharia. No entanto, a sensibilização para a economia circular só agora está a dar os primeiros passos.

\section{Economia Circular}

A própria natureza parece mostrar um novo caminho para ajudar a resolver o impasse entre indústria e meio-ambiente. Por intermédio da Biomimética, ciência que estuda modelos da natureza que podem servir de inspiração para resolver problemas humanos(BENYUS, 2009),observam-se ciclos de vida naturais onde o material orgânico morto se decompõe para se tornar um nutriente para a próxima geração de organismos vivos, num "circuito fechado" onde o desperdício torna-se um recurso(ANDREWS, 2015), princípio básico da Economia Circular.

Algumas escolas do pensamento foram fundamentais para a formação do conceito de economia circular. A "Economia de Performance", do químico Walter Stahel (1976) baseia-se na criação do maior valor de uso, no maior tempo possível, com o mínimo consumo de recursos materiais e energia possíveis. A "Ecologia Industrial" estuda os fluxos de materiais 
e energia nos sistemas industriais, de Frosch e Gallopoulos (1989), questionando porque é que o sistema industrial não se poderia comportar como um ecossistema, onde os resíduos de uma indústria serviriam de matéria-prima para outra, reduzindo assim recursos, poluição e gastos no tratamento de resíduos. O "Design Regenerativo", do arquiteto John Lyle (década de 70) enfatiza o desenvolvimento de sistemas que sejam capazes de ser restaurados, renovados, revitalizados ou regenerados através da integração dos processos naturais, da ação comunitária e do comportamento humano. O "Cradle to Cradle" - do berço ao berço, criado por Stahel e certificado pelo químico Michael Braungart e pelo arquiteto Bill McDonough, compreende os processos seguros e produtivos do "metabolismo biológico" da natureza, como um modelo para desenvolver um fluxo de "metabolismo técnico" de materiais industriais. A "Blue Economy", de Gunter Pauli (2004), que incentiva o uso dos recursos disponíveis em sistemas de cascata onde os resíduos de um produto se tornam matéria-prima para criar um novo fluxo, formam as bases do framework de economia circular conhecido atualmente (TOGNATO, 2018; ELLEN MACARTHUR FOUNDATION, 2019).

Ao dissociar a atividade económica do consumo de recursos finitos, apoiar-se em fontes de energia renovável e eliminar por princípio os resíduos do sistema, a economia circular é uma alternativa cada vez mais atraente que procura redefinir a noção de crescimento focando em benefícios para toda a sociedade e construindo um capital económico, natural e social (Figura 2).Numa economia circular, a atividade económica contribui para a saúde geral do sistema, não se limitando a ajustes que visem apenas a redução dos impactos negativos da economia linear (ELLEN MACARTHUR FOUNDATION, 2019). Éum modelo económico regenerativo e restaurador, em que os recursos (materiais, componentes, produtos, serviços) são geridos de modo a preservar o seu valor e utilidade pelo maior período de tempo possível, aumentando a produtividade dos recursos e preservando-se o capital natural bem como o capital financeiro das empresas e sociedade civil(ELLEN MACARTHUR FOUNDATION, 2015; REPÚBLICA PORTUGUESA - AMBIENTE, 2019).

linear

recursos naturais

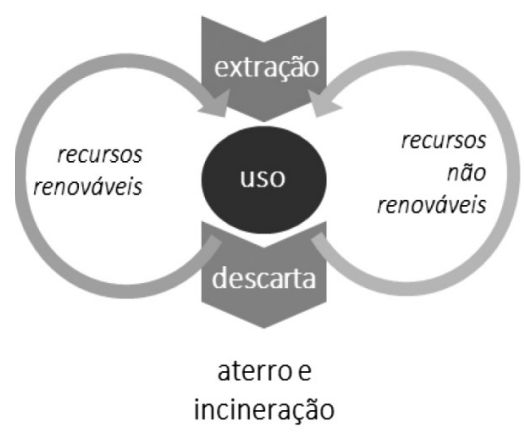

circular

recursos naturais

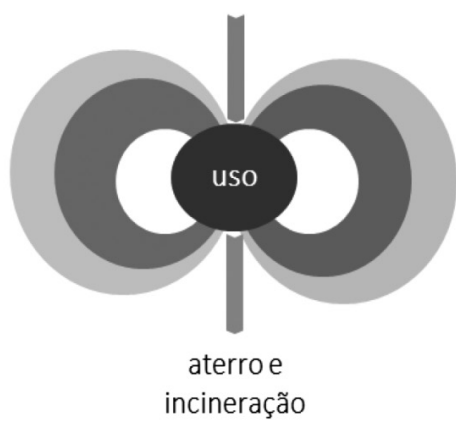

Figura 2. Economia Linear vs. Economia Circular (COSTA et al., 2018). 
O modelo circular, apresentado naFigura 3, faz uma distinção entre ciclos técnicos e biológicos. O consumo deve ocorrer apenas nos ciclos biológicos, onde materiais de base biológica (como alimentos, algodão e madeira) são planeados para retornar ao sistema por meio de processos como compostagem e digestão anaeróbica, regenerando os sistemas vivos, como o solo, que por sua vez proporcionam recursos renováveis para a economia. Os ciclos técnicos devem ser utilizados para recuperar e restaurar produtos, componentes e materiais por meio de estratégias como reuso, reparação, remanufatura ou, apenas em última instância, reciclagem. O sistema só é então considerado eficaz ao minimizar ao máximo as perdas e revelar as externalidades negativas do processo, excluindo-as dos projetos (ELLEN MACARTHUR FOUNDATION, 2019).

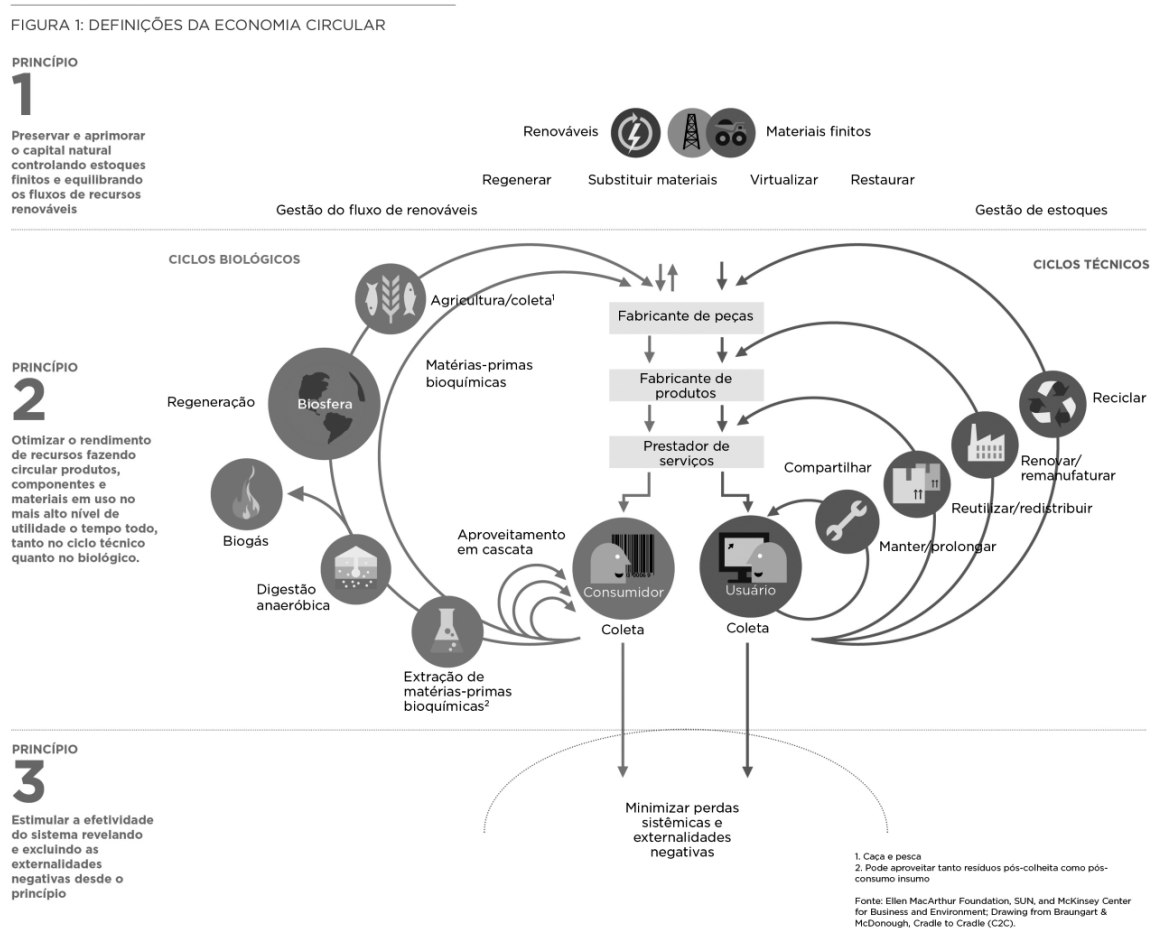

Figura 3. Princípios e Ciclos da Economia Circular (ELLEN MACARTHUR FOUNDATION, 2019).

Apesar da economia circular se basear em princípios voltados para a ação, devem-se considerar algumas características conceituais importantes no processo:criar resiliência por meio da diversidade, modularidade, versatilidade e adaptabilidade; transitar para o uso de energia 
proveniente de fontes renováveis; pensar em 'sistemas' e 'cascatas' não-lineares, ricos em feedback (retroalimentação), e interdependentes; e pensar em design sem resíduo:"resíduos não existem quando os componentes ou 'materiais' de um produto são projetados com a intenção de permanecerem dentro de um ciclo de materiais biológicos ou técnicos, concebidos para desmontagem e ressignificação" (ELLEN MACARTHUR FOUNDATION, 2019). Uma economia verdadeiramente circular tem de se concentrar em reter produtos ou componentes de vida finita e colocá-los de volta na cadeia de valor. É necessário pesquisa e desenvolvimento para redesenhar essas cadeias de valor, fechando o ciclo de materiais de recursos. Uma proposta de soluções práticas para este cenário inclui o uso de recursos de forma mais eficiente, a redução do lixo, a utilização do lixo como recurso, a substituição do "ter" pelo "compartilhar", a transformação dos produtos em serviços e o "bom" design dos produtos. Tudo em prol dos benefícios ambientais, económicos e sociais (EUROPEAN COMMISSION, 2017).

Como se pode observar no esquema proposto pela Comissão Europeia para alcançar a Economia Circular o design é uma peça chave (Figura 4). O desenho do produto tendo em consideração o seu fim de vida, as fontes dos recursos adotados, os serviços necessários para a sua produção e finalmente a sua utilização compartilhada, são agora dados de projeto fundamentais para conseguir alcançar o Design Circular, inevitável numa sociedade que está a perder vertiginosamente os seus recursos.

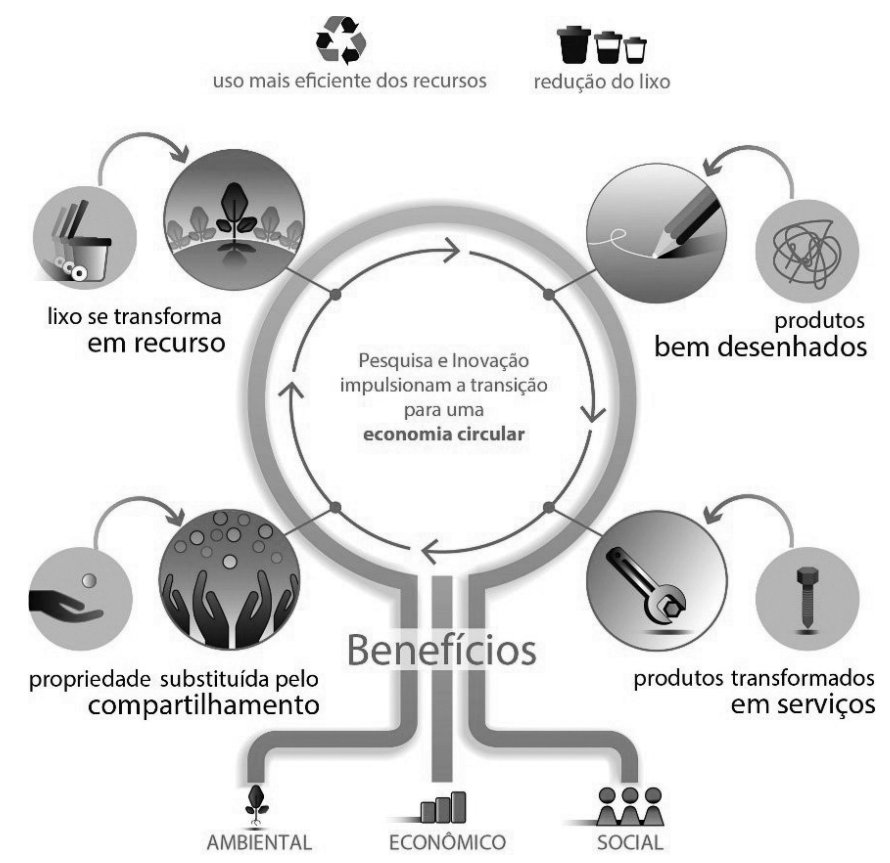

Figura 4. Soluções práticas para a economia circular (Adaptado de EUROPEAN COMMISSION, 2017). 


\section{Design Circular}

O termo comumente usado para representar a abordagem holística e mais representacional de "design circular" é o DfS (Design for Sustainability). Usado também para descrever a criação de objetos físicos e serviços para atender às necessidades sociais, económicas e ecológicas dentro de um determinado contexto, o DfS engloba uma descrição tanto para as abordagens preventivas (ecodesign) como para o design para ciclos fechados (MORE$\mathrm{NO}$ et al., 2016). Os designers têm a oportunidade de liderar a mudança de paradigma e, além de projetar para um "Ciclo de Vida de Produto Fechado", têm o potencial de influenciar o comportamento do consumidor e dos negócios, estendendo a vida real e aumentando o valor percebido dos produtos pelos usuários (ANDREWS, 2015; MORENO et al., 2016). Afinal de contas "nós não temos um problema com o lixo, nós temos um problema de design" (MCDONOUGH e BRAUNGART, 2002).

A economia global está crescendo de forma irregular, com altos e baixos, e tecnologias inovadoras desafiam os modelos de negócios estabelecidos. A circularidade tem um elevado potencial económico e é um condutor para uma economia moderna, com elevada relevância ambiental, contribuindo para os objetivos de desenvolvimento sustentável das Organizações das Nações Unidas - ONU (EUROPEAN COMMISSION, 2017).Para implementar uma economia circular, são necessárias inovações incrementais e disruptivas e o design tem desempenhado um papel fundamental nessa transição uma vez que é preciso educar e inspirar a indústria para assumir este desafioque,por ser uma mudança complexa, não consegue ser alcançada por intermédio de métodos de design tradicionais (RSA ACTION AND RESEARCH CENTRE, 2013; ELLEN MACARTHUR FOUNDATION; IDEO, 2017; MORENO et al., 2016). O designer tem assim uma importância fundamental na transmissão dessas preocupações para a comunidade empresarial e industrial.

$\mathrm{O}$ redesign dos processos de fabricação em torno dos princípios da economia circular tem o potencial de aumentar a reutilização e a reciclagem, criar novas oportunidades de negócio, abordar questões de segurança de materiais e contribuirpara um crescimento económico sustentável. O cerne do argumento é a necessidade de uma indústria transformadora que seja adequada aosseus propósitos e uma indústria de design que priorize o recurso como valor. "É inaceitável no século XXI que o mundo industrial estejaa operar através de um sistema ad-hoc baseado em modelos antigos da revolução industrial" (RSA ACTION AND RESEARCH CENTRE, 2013).

Os protagonistas dessa transformaçãonunca planearam tais consequências uma vez que a Revolução Industrialcomo um todo, não foi realmente projetada, mas foi tomando forma gradualmente conforme os industriais, engenheiros e designers solucionávamos problemas que iam encontrando e tiravam, assim, vantagem imediata das oportunidades que surgiam num período sem precedentes de mudanças rápidas e massivas (MCDONOUGH e BRAUNGART, 2002).

Hoje em dia, a escala do que está a ser projetado está a mudar de produtos e empresas, para sistemas económicos, estando a surgir um novo mindset de negócios (ELLEN MACARTHUR FOUNDATION; IDEO, 2017). Aproximadamente $80 \%$ do impacto ambiental de um produto pode ser "bloqueado" na fase de concepção do conceito, fazendo com que o design possa atuar não apenas no nível de eficiência do produto, mas no nível do sistema 
como um todo, reestruturando todo o negócio (RSA ACTION AND RESEARCH CENTRE, 2013; DESIGN COUNCIL, 2018). A fabricação corrente resulta em muito desperdício porque se concentra predominantemente no utilizador final, enquanto o princípio da economia circular é mais amplo, pois considera todos os stakeholders do sistema, desde quem extrai, constrói, usa, até quem descarta os materiais, evitando o desperdício em cada setor pela otimização de cada processo. O design circular utiliza ferramentas e métodos centrados no ser humano, baseados em pesquisas e observações de todo o ciclo de vida do produto, serviço ou sistema, incluindo os materiais utilizados e os processos de fabricação, colaborando com todas as partes interessadas da indústria e considerando as consequências não intencionais do processo (ELLEN MACARTHUR FOUNDATION; IDEO, 2017). O relatório britânico Investigating the Role of Design for the Circular Economy (RSA ACTION AND RESEARCH CENTRE, 2013) que investigou os desafios e oportunidades do design de produtos e sistemas para a economia circular, identificou quatro modelos de design que apresentam abordagens complementares para esse processo de transição, conforme apresentado na Figura 5. São eles:

- Design para longevidade: tendo como princípio estender o tempo de uso de um produto); - Design para serviço:procurando a criação de novos modelos de negócios, em que produtos passam a ser serviços, e consumidores se tornam usuários;

- Design para remanufatura:os produtos são projetados para que possam ser facilmente desmontados, consertados, reutilizados, revendidos ou reaproveitados;

Design para recuperação de materiais:procura-se que os materiais sejam aproveitados através da reciclagem (RSA ACTION AND RESEARCH CENTRE, 2013; IDEIA CIRCULAR, 2018).

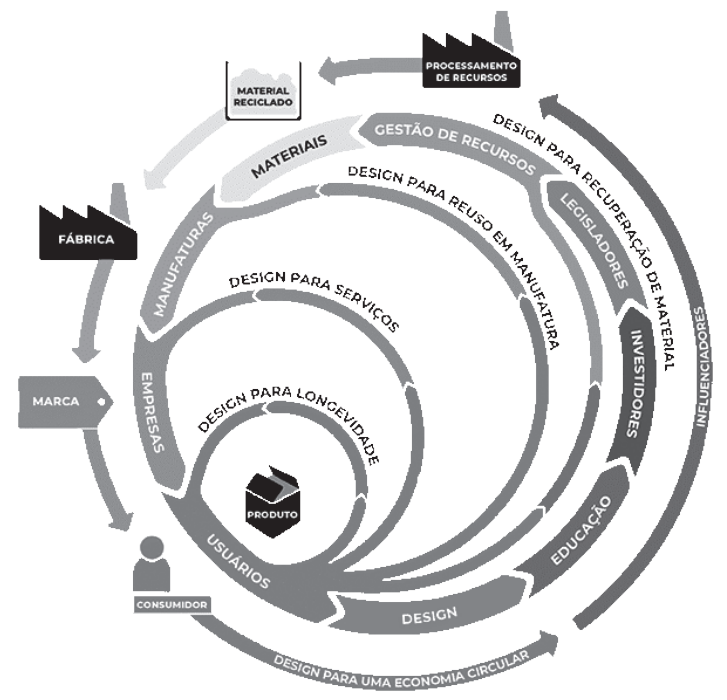

Figura 5. Modelos de Design para a Economia Circular (RSA ACTION AND RESEARCH CENTRE, 2013; IDEIA CIRCULAR, 2018). 
A IDEO e a Fundação Ellen Mac Arthur lançaram o primeiro guia de Design Thinking para a economia circular: The Circular Design Guide. O guia apresenta uma nova abordagem que introduz aos usuários deste novo cenário económico os conceitos de economia circular aliados às técnicas de Design Thinkingpor intermédio de 24 métodos divididos em quatro categorias: entender, definir, fazer e lançar. Essas categorias referem-se às fases sequenciais do projeto. Em cada uma delas são propostas seis tarefas para a concretização de cada passo ou categoria (Figura 6) (ELLEN MACARTHUR FOUNDATION; IDEO, 2017).
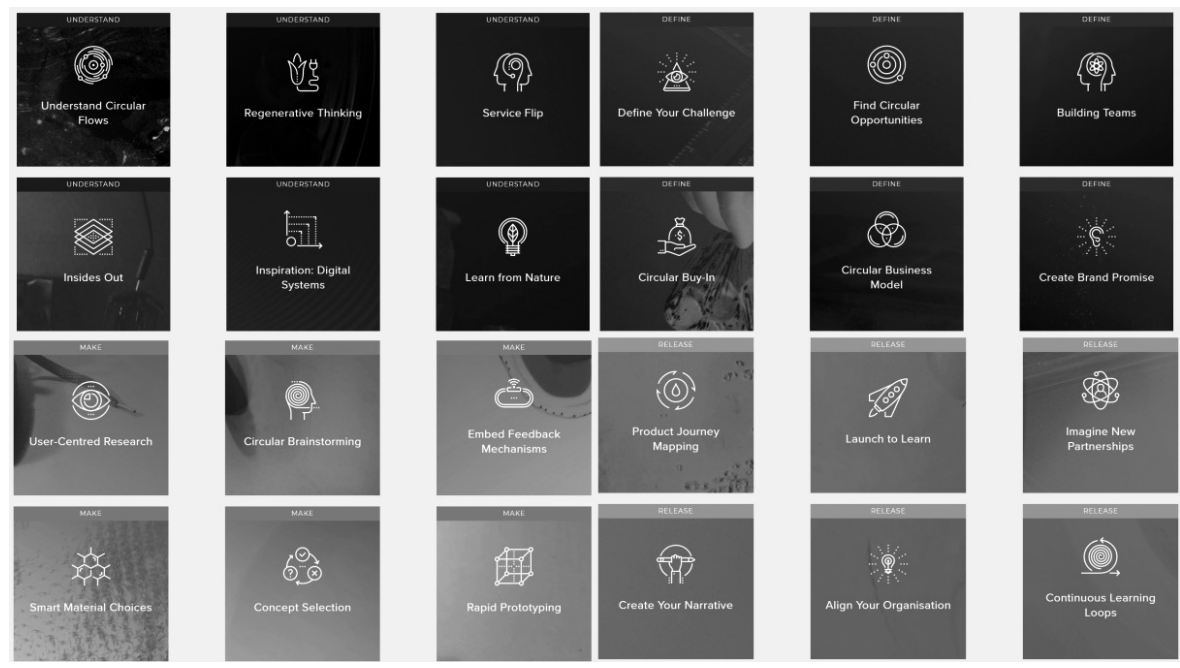

Figura 6. Métodos do Guia de Design Circular (ELLEN MACARTHUR FOUNDATION; IDEO, 2017).

O Circularity Workbook: Guiding the Future of Design é um guia desenvolvido pela Nike em parceria com estudantes e indústrias, direcionado aos designers e criadores de produtos e apresenta uma linguagem comum para a circularidade: criar produtos que duram mais e são projetados pensando no fim de vida, considerando a solução completa de design - como obter os materiais, como fabricar, como usar, como devolver à natureza e finalmente como repensar os próximos produtos (NIKE, 2019). O guia apresenta 10 princípios de design circular, conforme mostrado na Figura 7. Começando e terminado nos materiais, este método não sequencial propõe os seguintes temas durante a concepção do produto:

- Materiais - selecionar os que tenham menor impacto antes e após o uso do produto;

- Reciclabilidade - pensar como o produto poderá ser utilizado no seu fim de vida;

- Evitar desperdício - minimizar o desperdício durante o processo de produção;

- Desmontagem - procurar soluções cuja desmontagem seja facilitada;

- Química verde - evitar o uso de matérias tóxicas;

- Reparação - procurar soluções com reparação fácil; 
- Versatilidade - adotar conceitos independentes de modas ou tendências;

- Durabilidade - procurar soluções com tempo de vida prolongado;

- Circular Packaging - adotar soluções que respondam aos três R's: reutilizar, reparar ou reciclar;

- Novos modelos-propor novos modelos de negócio para estender o ciclo de vida dos produtos.

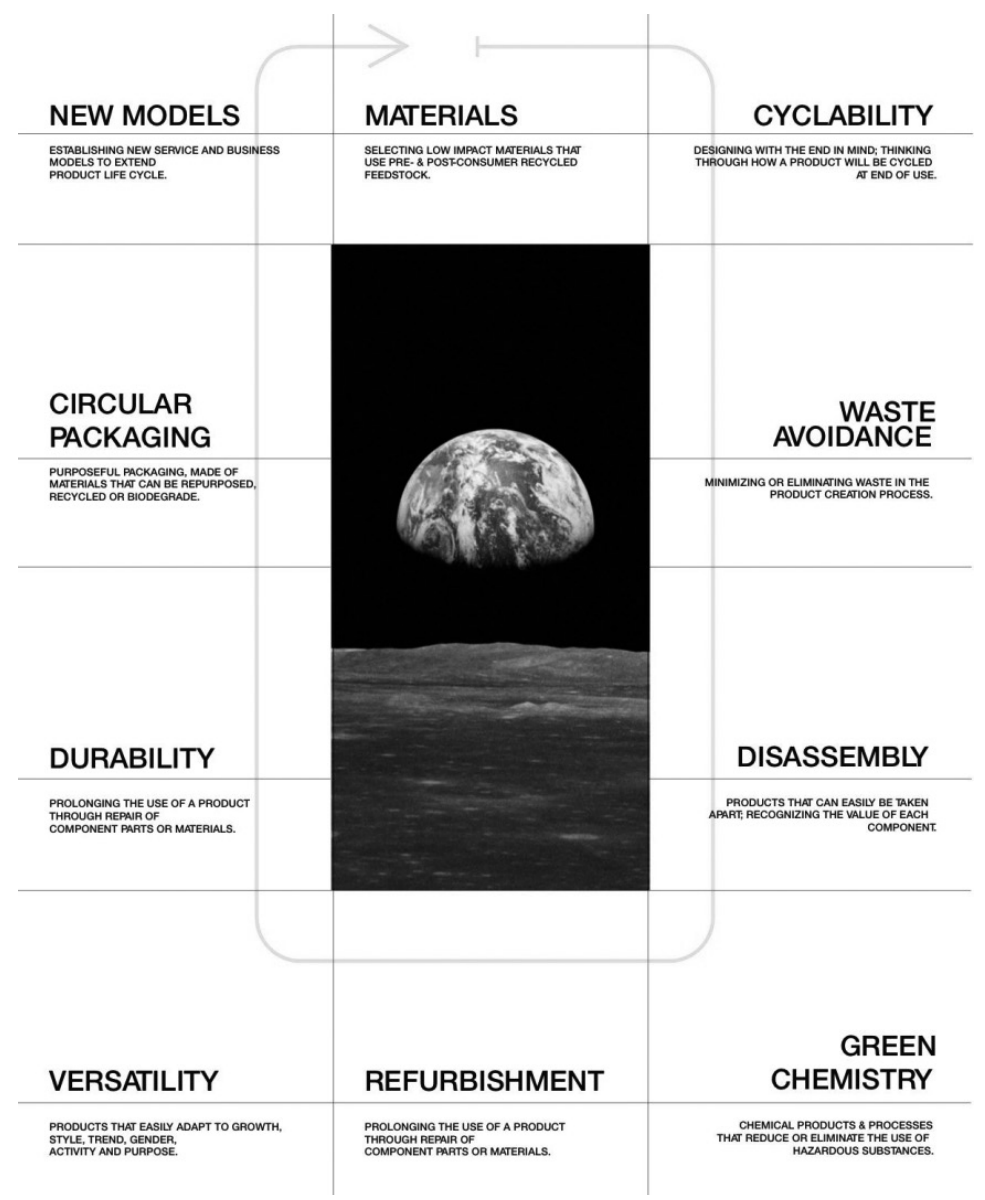

Figura 7. 10 Princípios de Design Circular (NIKE, 2019).

O entendimento, a investigação e a aplicação de princípios de design circular são tarefas que não se restringem aos profissionais de design. Para alcançar essa transformação sistémica, é necessário repensar e redesenhar novos produtos, sistemas e modelos de negócios que conduzam para uma transição para a economia circular, num projeto que vai precisar 
da contribuição multidisciplinar de pessoas de todas as áreas de atuação e conhecimento. É possível descobrir novas formas de habitar o planeta e novas formas de se relacionar com os recursos e produzir riqueza. O design circular pode ser uma das chaves para gerar prosperidade económica, social e ecológica, que se sustente no longo prazo, num sistema restaurador e regenerativo, direcionado para uma inovação circular (ELLEN MACARTHUR FOUNDATION; IDEO, 2017; IDEIA CIRCULAR, 2018).

\section{Educação para uma inovação circular}

O conceito de economia circular está a ganharprotagonismo em termos de negócios. Governo e academia e a educação têm desempenhado um papel fundamental no desafio de como refletir sobrea atual economia linear, e comoesta temática deve ajudar a inspirar e fornecer ferramentas para criar uma narrativa positivapara o futuro, de acordo com as ciências dos sistemas complexos. As questões sobre "como" ensinar sobre uma economia circular são tão importantes quanto "o quê" ensinar neste contexto,não apenas para ajudar a entender melhor a economia circular, mas também para entender como é o processo de transição para ela (FORSLUND, CLINTON e WEBSTER, 2018).Uma das principais recomendações para o aperfeiçoamento da indústria é preparar as futuras gerações incorporando a circularidade no sistema educacional. A educação para a sustentabilidade não deve ser deixada para trás ou adicionada como um pensamento de última hora,mas sim, deve ser incorporadanos currículos em todos os cursos de design e engenharia, incentivando a aprendizagem multidisciplinar e transcultural, com base na compreensão do ciclo de vida dos produtos e serviços, a fim de conectar designers, engenheiros, especialistas em materiais, antropólogos, "marketeiros" e gestores (RSA ACTION AND RESEARCH CENTRE, 2013; ANDREWS, 2015). Em 2018, a Fundação Ellen MacArthur realizou uma pesquisa para mapear o atual panorama global das ofertas de aprendizagem da economia circular no ensino superior. Foram considerados os programas de bacharelado e mestrado que ofereciam a economia circular no título ou na descrição do curso. Foram encontradas 138 instituições de ensino superior com 51 ofertas de aprendizagem de economia circular - em inglês, holandês, finlandês e chinês (línguas já conhecidas porterem a maior atividade de ofertas nessa área), conforme apresentado na Figura 8. A maioria das ofertas de aprendizagem relacionadas com a economia circular foram encontradas nos estudos tradicionais focados na sustentabilidade, engenharia, negócios, design e inovação, envolvendo temas como: aspectos ambientais, aspectos sociais, alavancas políticas, tecnologia digital, ecodesign, serviços, modelos de negócios circulares e pensamento de sistemas. O relatório conclui que esta pesquisa destaca um impulso nascente na criação de ofertas, recursos e aproximações de aprendizagem da economia circular, com determinadas localizações geográficas como pioneiras neste assunto. Entretanto, são necessárias mais pesquisas para se conhecer as ofertas disponíveis em outras línguas, como o português por exemplo, ou que não são visíveis online, ou que não são explicitamente rotuladas economia circular, mas, no entanto, concentram-se em perspectivas relevantes (FORSLUND, CLINTON e WEBSTER, 2018). 


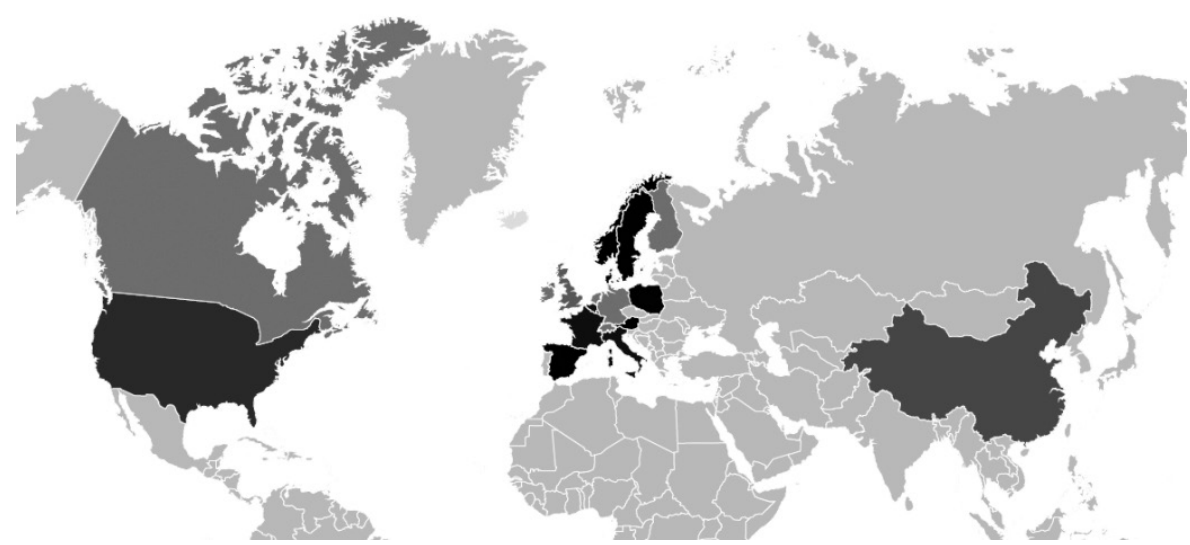

Figura 8. Instituições de ensino superior com ofertas de aprendizagem da economia circular (FORSLUND, CLINTON e WEBSTER, 2018).

Projetar para a circularidade envolve uma grande rede de participantes desde a cadeia de suprimentos tradicional até aos políticos, investidores e educadores. O Diagrama de Rede Circular (Figura 9) mapeia os stakeholders que fazem parte do sistema de economia circular, mostrando que, apesar de não haver uma hierarquia, todos os intervenientes de várias áreas têm igual importância e cada um assume seu "segmento" no círculo e deve reconhecer a importância de trabalhar com os outros. É assim evidente a necessidade de educar, desde os primeiros anos de formação, todos os participantes, tanto engenheiros como designers, marketeers ou investidores.

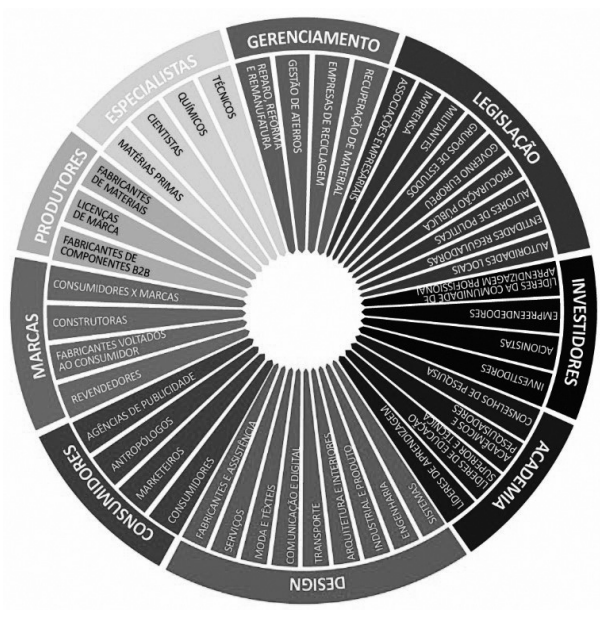

Figura 9. Diagrama da rede circular (Adaptado de RSA GREAT RECOVERY, INNOVATE UK, 2016). 